\title{
REVIEW
}

\section{Wind turbine underwater noise and marine mammals: implications of current knowledge and data needs}

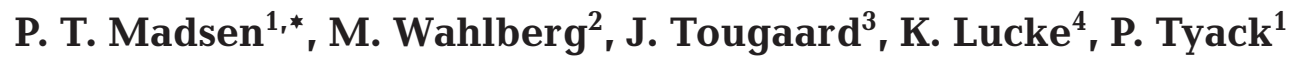 \\ ${ }^{1}$ Woods Hole Oceanographic Institution, Biology Department, Woods Hole, Massachusetts 02543, USA \\ ${ }^{2}$ Department of Zoophysiology, Biological Institute, Aarhus University, 8000C Aarhus, Denmark \\ ${ }^{3}$ National Environmental Research Institute, Department of Arctic Environment, 4000 Roskilde, Denmark \\ ${ }^{4}$ Science and Research Centre, University of Kiel, 25761 Büsum, Germany
}

\begin{abstract}
The demand for renewable energy has led to construction of offshore wind farms with high-power turbines, and many more wind farms are being planned for the shallow waters of the world's marine habitats. The growth of offshore wind farms has raised concerns about their impact on the marine environment. Marine mammals use sound for foraging, orientation and communication and are therefore possibly susceptible to negative effects of man-made noise generated from constructing and operating large offshore wind turbines. This paper reviews the existing literature and assesses zones of impact from different noise-generating activities in conjunction with wind farms on 4 representative shallow-water species of marine mammals. Construction involves many types of activities that can generate high sound pressure levels, and pile-driving seems to be the noisiest of all. Both the literature and modeling show that pile-driving and other activities that generate intense impulses during construction are likely to disrupt the behavior of marine mammals at ranges of many kilometers, and that these activities have the potential to induce hearing impairment at close range. The reported noise levels from operating wind turbines are low, and are unlikely to impair hearing in marine mammals. The impact zones for marine mammals from operating wind turbines depend on the low-frequency hearing-abilities of the species in question, on sound-propagation conditions, and on the presence of other noise sources such as shipping. The noise impact on marine mammals is more severe during the construction of wind farms than during their operation.
\end{abstract}

KEY WORDS: Marine mammal $\cdot$ Wind turbine $\cdot$ Pile-driving $\cdot$ Underwater noise $\cdot$ Impact zones Masking

Resale or republication not permitted without written consent of the publisher

\section{INTRODUCTION}

Increased focus on the exploitation of renewable sources of energy has led to construction of offshore wind farms with turbines generating electrical power of several megawatts. The 2 largest offshore wind farms, operating with nominal power outputs of 160 megawatts, have recently been established in shallow waters off the coast of Denmark, and many more are planned for northern Europe and North America. Offshore wind farms have so far been constructed in shallow waters
$(<20 \mathrm{~m})$, but the potential for placing them in 20 to $100 \mathrm{~m}$ is currently being explored. A high productivity and a rich marine life often characterize such nearshore habitats, and the construction and operation of large wind turbines has therefore raised concern about impacts on the marine environment (Koschinski et al. 2003, NRC 2003). One of the possible negative effects relates to low-frequency underwater noise generated during the construction and operation of wind turbines. Most marine vertebrates use sound for communication, orientation and/or foraging (Tyack 1998), and 
are therefore potentially susceptible to elevated levels of anthropogenic noise that may impair reception of auditory cues or disrupt normal behavior (Richardson et al. 1995). Wahlberg \& Westerberg (2005) recently reviewed and assessed the impact of underwater noise from wind turbines on fishes. They concluded that windmill noise could potentially affect fish behavior at ranges of several kilometers, but they also pointed out that available data on windmill sound production and fish behavior is too rudimentary to clarify if noise from wind farms is actually causing any problems for fishes. The wind turbine noise is of too low intensity to cause permanent or transient hearing impairment in fishes, even at ranges of a few meters from the wind turbines (Wahlberg \& Westerberg 2005).

Despite a number of gray literature reports, little peer-reviewed information is available about the noise effects of offshore wind farms on marine mammals. This paper critically reviews the existing gray literature and uses published data on underwater noise from operating wind turbines to estimate zones of impact on representative marine mammal species in shallowwater habitats. We address the implications for the effects of wind farms on different marine mammal groups in the context of other anthropogenic noise sources and discuss possible avenues for future research.

\section{MARINE MAMMAL HEARING AND NOISE}

Considering the geographical areas currently used for wind farms and the limited depth range in which they are placed, we focus on selected species of shallow-water pinnipeds and cetaceans, and leave the consideration of effects on sea otters, manatees, deepwater cetaceans and pinnipeds for future studies if, and when, relevant. More specifically, we assess the possible impact of wind turbine noise on 4 species representative of mammalian groups living in shallowwater offshore habitats suitable for wind farms. These representative species include 3 cetaceans, the harbor porpoise Phocoena phocoena, the bottlenose dolphin Tursiops truncatus, the northern right whale Eubalaena glacialis, and a pinniped, the harbor seal Phoca vitulina. Baleen whales may not be relevant to the discussion of effects of wind farms in very shallow water. If, however, wind farms are to be constructed in waters deeper than $20 \mathrm{~m}$, we argue that a baleen whale species living in coastal waters, like the northern right whale, should be included in the impact assessment. We do not address possible indirect effects on marine mammals such as the possible impact of noise on their prey items (see Wahlberg \& Westerberg 2005).

Pinnipeds (seals) and cetaceans (whales, dolphins and porpoises) have adapted their sensory systems to an entirely aquatic (cetacean) or amphibious (pinniped) life style. Cetaceans produce and receive sound over a great range of frequencies for use in communication, orientation, predator avoidance and foraging (Tyack 1998). The large baleen whales generate lowfrequency, long-duration, powerful calls that in some cases may have ocean-traversing potential (Payne \& Webb 1971, Stafford et al. 1998), whereas the echolocating, toothed whales generate short, ultrasonic transients (clicks) for navigation and echolocation of prey at ranges of tens to hundreds of meters (Au 1993). Most delphinid toothed whales also produce frequencymodulated whistles for communicative purposes (Tyack 1998). Thus, baleen whales produce sounds for communication and possibly navigation in the frequency range from $10 \mathrm{~Hz}$ to $10 \mathrm{kHz}$, whereas toothed whales produce sounds for echolocation and communication in the frequency range from 1 to $150 \mathrm{kHz}$ (Richardson et al. 1995). Pinnipeds communicate by vocalizing in the frequency range from $50 \mathrm{~Hz}$ to about $60 \mathrm{kHz}$ (Richardson et al. 1995).

Smaller toothed whales can hear frequencies over a range of 12 octaves, with their most sensitive hearingrange in a frequency band roughly overlapping the frequency content of their echolocation clicks ( $\mathrm{Au}$ 1993, Richardson et al. 1995). The detection of a signal by a marine mammal ear is affected by interference from noise in frequency bands near that signal (e.g. Au \& Moore 1990, Erbe \& Farmer 1998, Southall et al. 2001, Finneran et al. 2002) as is the case for biological receivers in general. The interference effects of such noise is called masking, and the width of the frequency band in which additional noise causes masking of a pure tone is called the critical band (reviewed by [e.g.] Richardson et al. 1995; see also Scharf 1970). The mammalian ear can be modeled as a series of bandpass filters, whereby signal sound energy and noise are integrated within these filters. This has important implications for how noise should be quantified in a way meaningful to marine mammals. A common practice in noise studies is to plot noise in units of power spectral density ( $\mathrm{dB}$ re $1 \mathrm{\mu Pa}^{2} \mathrm{~Hz}^{-1}$ ), where the noise power is given in $1 \mathrm{~Hz}$ bands. However, this measure has very little relevance for how marine mammals perceive noise, as it does not incorporate the critical bands of the mammalian auditory system. It is thus misleading to compare audiograms and power spectrumdensity levels. In order to make a meaningful comparison between broadband noise and audiograms, the noise power must be given in the relevant critical bands, rather than in units of spectral density level. A common first approximation of critical bands in mammals is that the width is a fixed percentile of the center frequency of the band, a so-called constant Q-filter bank $(Q$ being the ratio of center frequency over band- 
width). Various measurements of critical bandwidth in different species of marine mammals exist, ranging from approximately two-thirds to one-twelfth of an octave (Au \& Moore 1990, Erbe \& Farmer 1998, Southall et al. 2001). For simplicity, and in agreement with common practice for such measurements (Richardson et al. 1995), we use a bandwidth of onethird octave in the following and thus give noise measurements as third-octave RMS sound pressure levels (third-octave levels, TOLs) in units of $\mathrm{dB}$ re $1 \mu \mathrm{Pa}$ (RMS). The TOLs of white noise are calculated from noise spectral density as:

$$
\begin{aligned}
\mathrm{TOL} & =N_{0}(f)+10 \log \mathrm{BW} \\
& =N_{0}+10 \log \left[f\left(2^{1 / 6}-2^{-1 / 6}\right)\right] \\
& \approx N_{0}(f)+10 \log (0.23 f)
\end{aligned}
$$

where $N_{0}$ is the noise power spectrum level ( $\mathrm{dB}$ re $1 \mu \mathrm{Pa}^{2}$ $\mathrm{Hz}^{-1}$ ) and $f$ and BW are the center frequency and bandwidth of the given TOL. TOLs can also be measured directly by using analog or digital TOL filter banks in concert with an RMS sound level meter. At low frequencies outside the range of best hearing, most animals investigated have critical bands covering a broader frequency range than expected from the constant Q rule (e.g. Johnson et al. 1989). This means that their detection of sound in noise will be poorer at these frequencies than expected when compared to a constant Q filter bank (Richardson et al. 1995). Low-frequency hearing specialists on the other hand are likely to maintain constant $\mathrm{Q}$ auditory filters also at very low frequencies. Even if no animal can be expected to have an auditory system equivalent to a bank of precisely one-third-octave filters, the TOL measure is a useful first approximation for understanding how a mammalian auditory system perceives and is affected by noise, and how detection of narrow-band signals is affected. When detecting broadband sounds, such as from transients, the auditory system will integrate noise over the signal bandwidths that often will be larger than 1 or more critical bands. In these cases, the RMS-bandwidth of the signal may be a more relevant measure for the bandwidth over which masking noise is integrated (Au et al. 2004).

Detection of a signal is limited either by internal noise in the auditory system (hearing threshold) or ambient noise in 1 or more critical bands (masking threshold). The pure-tone hearing threshold in the range of best hearing of marine mammals is normally well below ambient noise TOL at the same frequencies, implying that ambient noise will limit detection in the frequency range of best hearing, and that increasing ambient noise levels will mask the detection of incoming sounds in the same frequency bands, i.e. increased noise leads to higher detection thresholds. This phenomenon is illustrated in Fig. 1, where pure-
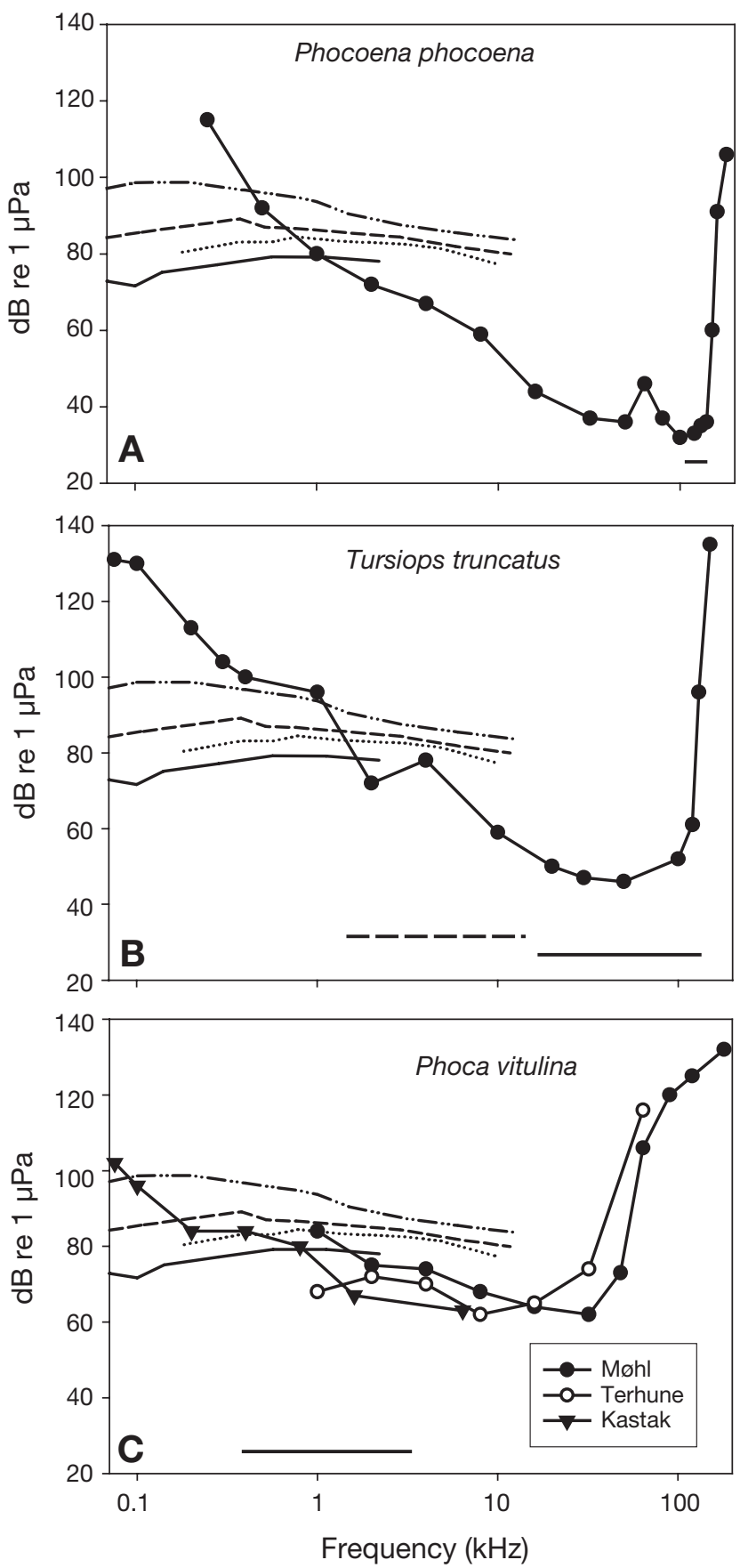

Fig. 1. (A) Phocoena phocoena; (B) Tursiops truncatus; (C) Phoca vitulina. Audiograms of harbor porpoise, bottlenose dolphin and 3 harbor seals, and ambient third-octave sound pressure levels (TOLs) in dB re $1 \mu \mathrm{Pa}$ (RMS) recorded at wind speeds of $5 \mathrm{~m} \mathrm{~s}^{-1}$ in 4 different shallow-water habitats. Continuous line: Scotian shelf (Piggot 1964); dotted line: Eastern Pacific (Wenz 1962); dashed line: Baltic (Willie \& Geyer 1984); dot-dashed line: North Sea (Willie \& Geyer 1984). Horizontal lines below audiograms indicate approximate frequency ranges of vocalizations; for $T$. truncatus, dashed line = whistles; continuous line = clicks. Audiograms from (A) Kastelein et al. (2002), (B) Johnson (1967), and (C) Møhl (1968), Terhune \& Turnbull (1995) and Kastak \& Schusterman (1998) 
tone audiograms of a harbor porpoise, a bottlenose dolphin and 3 harbor seals are plotted along with ambient noise TOL at wind speeds of $5 \mathrm{~m} \mathrm{~s}^{-1}$ in different shallow-water habitats. The low-frequency ambient noise level of shallow-water habitats increases rapidly with increasing wind speeds. We focus on wind speeds between 5 and $13 \mathrm{~m} \mathrm{~s}^{-1}$ as this interval is most interesting from the perspective of wind farm operation. Wind turbines do not operate at very low or very high wind speeds above some $20 \mathrm{~m} \mathrm{~s}^{-1}$.

There is a general overlap in the frequency range of best hearing and the frequency range at which the different species produce sound for communication or echolocation. The harbor porpoise and the bottlenose dolphin, which do not produce sounds at low frequencies, have quite insensitive hearing at frequencies below $1 \mathrm{kHz}$ (Fig. 1A,B). As a consequence, the detection of low-frequency sounds in these species is limited by the hearing threshold rather than by the ambient noise TOLs (Fig. 1A,B). The harbor seal, on the other hand, produces sounds down to $100 \mathrm{~Hz}$ and has a fairly good low-frequency hearing sensitivity, with hearing thresholds close to or below the ambient noise TOL (Fig. 1C). This suggests that the harbor seal could be limited by the ambient noise rather than hearing threshold in the frequency range from $100 \mathrm{~Hz}$ to $1 \mathrm{kHz}$ at wind speeds of $5 \mathrm{~m} \mathrm{~s}^{-1}$ and higher. Unfortunately, there are no psychophysical or physiological data on the hearing capabilities of baleen whales, but anatomical investigations suggest that these species have their best range of hearing at low frequencies below $1 \mathrm{kHz}$ (Ketten 2000). The vocal repertoire of the northern right whale primarily involves the frequency range from $50 \mathrm{~Hz}$ to $2 \mathrm{kHz}$ (Parks \& Tyack 2005), which is consistent with the notion that it is a low-frequency hearing-specialist. We therefore assume that acoustic detection by the northern right whale and other baleen whales is limited by ambient noise at low frequencies rather than the hearing threshold at wind speeds of $5 \mathrm{~m} \mathrm{~s}^{-1}$ and higher.

Noise can be defined as sound that impairs reception of signals of interest or that affects the animal in a way that disrupts normal behavior (Richardson et al. 1995). The effects of man-made noise on marine mammals have been reviewed in several books (e.g. Richardson et al. 1995, NRC 2000, 2003), and the area has received increasing public and scientific attention the last decade. Depending on the source properties and the habitat in which the sounds propagate, sound sources may impact marine mammals in different ways at variable ranges. In their seminal review Richardson et al. (1995) defined 4 zones of impact around an anthropogenic sound source: (1) the zone of audibility, (2) the zone of responsiveness, (3) the zone of masking, and (4) the zone of injury. Accordingly, for the first 2 impact zones anthropogenic noise should be treated as a sig- nal that the animal must detect, whereas the anthropogenic noise should be treated as an addition to the ambient noise in the case of the zone of masking.

The extent of the zone of audibility (Zone 1) is defined as the range at which the animal can barely detect the sound source. In the current study, we assume that detection of the sound signal will be possible when the received level either matches the hearing threshold at that given frequency, or the ambient noise TOL at that frequency if noise TOL is higher than the hearing threshold. This definition is reasonable in cases where the noise is broadband. If the noise in question has most energy at discrete frequencies or otherwise has tonal qualities (as is the case for the most prominent types of turbine sounds discussed in next subsection), the detection may be possible down to levels some decibels below the ambient noise (Scharf 1970, Au 1993), but we maintain the above definition for the sake of simplicity.

The zone of responsiveness (Zone 2) is defined as the zone in which the animal responds to the sound exposure behaviorally or physiologically. This zone will normally be significantly smaller than the zone of audibility. The zone of responsiveness is by far the most challenging to estimate, since it requires intimate knowledge about how the animal may alter its behavior when exposed to noise with different spectral and temporal properties. Probably the most difficult aspect of the zone of responsiveness is that behavioral responses may be both difficult to define and detect. In addition, thresholds for changes in behavior may differ greatly among individuals and for a single individual in different contexts. The zone of responsiveness is thus unlikely to be represented by a single sound level, but rather defined by a dose-response function that is context-dependent and where sensitization or habituation may come in to play (Richardson et al. 1995).

The zone of masking (Zone 3 ) is defined as the range at which the anthropogenic noise adds significant energy to the ambient noise in frequency bands that overlap with signals of interest. Addition of such masking noise will lower the probability of detection of a signal by lowering the signal-to-noise ratio and thus, in effect, increase the detection threshold. Masking only occurs in those cases where detection is limited by ambient noise and not by the absolute hearing threshold of the animal. We define significant masking as an increase of $3 \mathrm{~dB}$ in the ambient noise TOL caused by the masking sound. This occurs when the TOL of the masking sound equals the ambient noise TOL, so under certain circumstances the zones of masking and audibility are the same when using these criteria. As with the zone of audibility, this definition is not completely correct in case of noise with spectral peaks, as the masking power of continuous pure tones is signifi- 
cantly lower than that of broadband random noise (Green 1969, Zwicker \& Schorn 1978).

The zone of injury (Zone 4 ) is defined as the range at which the received sound pressure levels are so high that the animal may suffer from direct physical injury or loss of sensitivity in its auditory system. The experimental indicator of risk of injury usually stems from temporary threshold shift (TTS) experiments. Experiments with marine mammals show a nearly linear relationship between sound exposure level and duration of exposure: the longer an animal is exposed, the lower the level required to produce TTS (Kastak \& Schusterman 1999, Schlundt et al. 2000, Nachtigall et al. 2003). From a regulatory perspective, injury is normally an issue of concern when the received broadband sound pressure levels exceed $180 \mathrm{~dB}$ re $1 \mu \mathrm{Pa}$ (RMS) for cetaceans and $190 \mathrm{~dB}$ re $1 \mu \mathrm{Pa}$ (RMS) for pinnipeds (NMFS 2003). Recent data by Nachtigall et al. (2004) have shown that broadband noise exposure between 4 and $11 \mathrm{kHz}$ for $30 \mathrm{~min}$ at received levels of around $160 \mathrm{~dB}$ re $1 \mu \mathrm{Pa}$ (RMS) cause TTS in a dolphin (Tursiops truncatus). This implies that the $180 \mathrm{~dB}$ re $1 \mu \mathrm{Pa}$ (RMS) criterion by NMFS (2000) may have to be reconsidered, and that the zone of injury, if judged to include TTS, is considerably larger than that estimated here for long durations of exposure. Also, the $180 \mathrm{~dB}$ criterion has problems of its own when comparing impacts of transient sounds (such as pile-driving sound; see next subsection) and continuous sounds (such as wind turbine noise) (see Madsen 2005 for further discussion on this topic). The level of impact of sounds impinging on the auditory system is frequency-dependent and noise levels should (as for humans) ideally be weighted with the frequency response of the auditory system for the animal in question. The data available to do this are unfor-

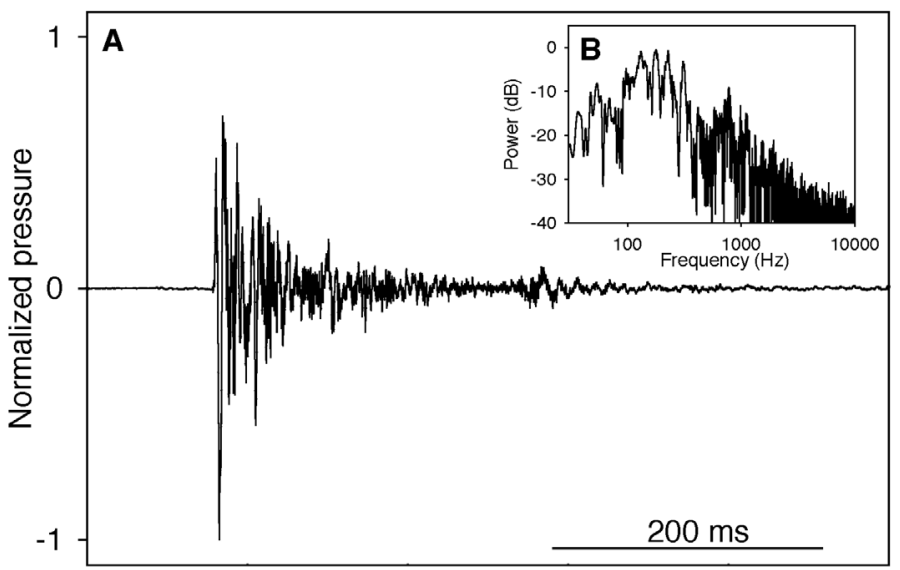

Fig. 2. (A) Acoustic signal measured from $500 \mathrm{~kJ}$ hydraulic hammer; (B) power spectrum (FFT size $=1840$, bin width $=$ $6 \mathrm{~Hz}$ ) of waveform of (A). Data from Rodkin \& Reyff (2004) and Illilngworth \& Rodkin, Petaluma, California tunately very sparse, and accordingly we do not feel that differential weighting of the pile-driving sound levels for assessing the zone of injury would be made more reliable by comparison between species.

In the following, we will use the impact zones of Richardson et al. (1995) as defined above (Zones 1 to 4 ) for assessment of the possible impact of noise generated from constructing and operating offshore wind turbines.

\section{NOISE PROFILES FROM CONSTRUCTION AND OPERATION OF WINDMILLS}

Underwater noise is produced both during construction and operation of offshore wind farms. Construction often includes an array of activities, including profiling, shipping, pile-driving, trenching and dredging (Nedwell \& Howell 2004). All these activities will produce underwater noise of varying intensity, duration and spectra (Richardson et al. 1995). When considering anthropogenic noise effects on marine mammals in conjunction with construction of wind farms, we regard pile-driving to be of special concern, as it generates signals of a very high source level and broad bandwidth (Richardson et al. 1995). This does not mean that other less noisy sound sources can be ignored, but the problems associated with the piledriving represent worse case scenarios that may be applicable for assessing the impact of a range of less noisy construction activities.

Offshore wind turbines are supported by different foundation types including steel monopile and gravitational concrete foundations. Monopile foundations are rammed into the seabed using a pile-driver (McKenzie Macon 2000) or by vibration. Usually it takes several hours to drive 1 monopile into the bottom, depending on the sediment type. The blows are delivered at approximately $1 \mathrm{~s}$ intervals. Pile-driving is not used for gravitational concrete foundations in sheltered waters, so the peak-level noise impact from implementation of this foundation type is much lower and of a different nature. Pile-driving is therefore not necessarily an inherent part of wind farm construction.

Underwater noise from pile-driving has been measured in several studies (Nedwell et al. 2003, Betke et al. 2004, Blackwell et al. 2004, Rodkin \& Reyff 2004). The size of the hammer and the monopile as well as the properties of the seafloor influence the source level and frequency content of the signals generated (Rodkin \& Reyff 2004 (additional data supplied by Rodkin \& Reyff, Illingworth \& Rodkin, Petaluma, California). Because of the size of wind turbine foundations, very large pile-driving units are used. The temporal and frequency content of the sound from a large piledriving unit is depicted in Fig. 2. There is a frequency 
Table 1. Properties of wind turbines for which underwater sounds have been recorded

\begin{tabular}{|lcllccl|}
\hline Location & $\begin{array}{c}\text { Power } \\
\text { (MW) }\end{array}$ & Model & Foundation & $\begin{array}{c}\text { Depth } \\
(\mathrm{m})\end{array}$ & $\begin{array}{c}\text { No. of } \\
\text { turbines }\end{array}$ & Source \\
\hline Nogersund & 0.2 & Windworld & Tripod & $5-15$ & 1 & Westerberg (1994) \\
Vindeby & 0.5 & Bonus & Concrete gravitational & $2-4$ & 11 & Degn (2000) \\
Utgrunden & 1.5 & GE Wind & Monopile & $5-10$ & 7 & Ingemansson (2003) \\
Bockstigen & 0.6 & Windworld & Monopile & 10 & 5 & Degn (2000), Fristedt et al. (2001) \\
Middelgrunden & 2.0 & Bonus & Concrete gravitational & 5 & 20 & Henriksen (2001) \\
North Hoyle & 2.0 & Vestas & Monopile & 10 & 30 & Nedwell et al. (2003) \\
Mecklenburg & 1.5 & GE Wind & Monopile & 10 & 50 & Betke et al. (2004) \\
Horns Reef & 2.0 & Vestas & Monopile & $8-14$ & 80 & Anonymous (2002) \\
\hline
\end{tabular}

emphasis below some $500 \mathrm{~Hz}$, even though frequency components can extend into the ultrasonic frequency range. The received level can be above $200 \mathrm{~dB}$ re $1 \mu \mathrm{Pa}$ (RMS) at 100 m distance (Anonymous 2001) (see Madsen 2005 for problems with RMS measures for transients). Due to the impact nature of the sound source, the sound radiation pattern from pile-driving is assumed to be rather omnidirectional, although its directionality to our knowledge has never been assessed.

Underwater acoustic measurements at offshore wind turbines have been made in Sweden, Denmark and Germany (Westerberg 1994, Degn 2000, Fristedt et al.

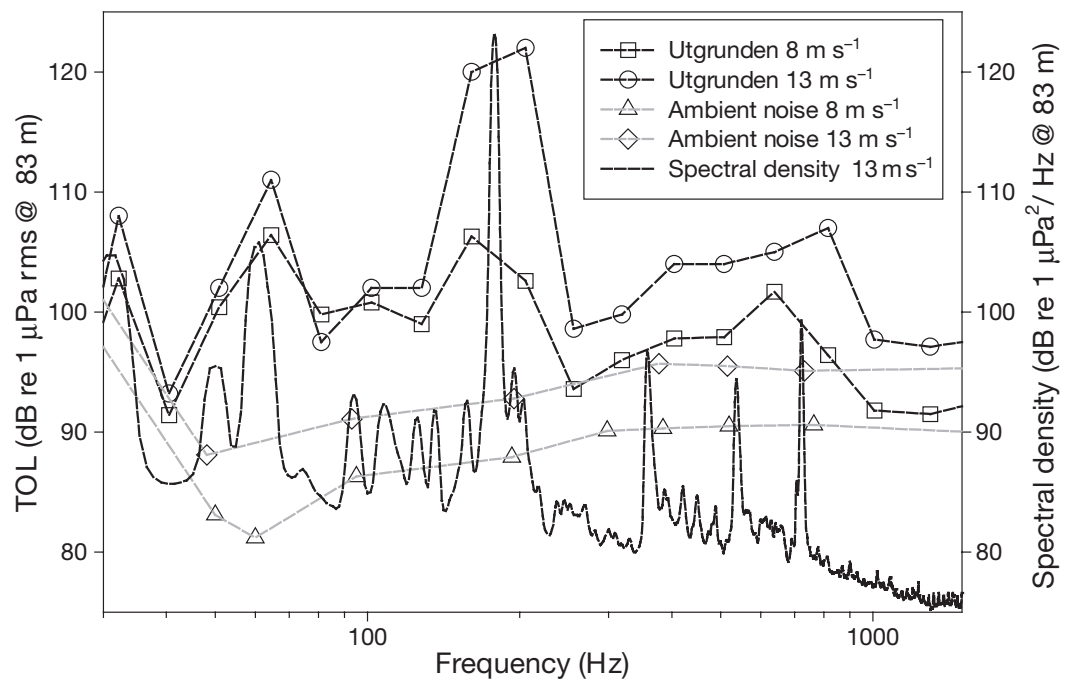

Fig. 3. Noise from wind turbine (Utgrunden wind farm) recorded in the Baltic Sea in third-octave levels (TOL dB re $1 \mu \mathrm{Pa}$ RMS) at wind speeds of 8 and $13 \mathrm{~m} \mathrm{~s}^{-1}$ and as spectral noise density $\left(\mathrm{dB}\right.$ re $\left.1 \mu \mathrm{Pa}^{2} \mathrm{~Hz}^{-1}\right)$ at $13 \mathrm{~m} \mathrm{~s}^{-1}$ (spectral density). Measurements are averages of at least 3 min recorded data. Ambient noise levels measured in the southern Baltic Sea (thirdoctave levels, TOL dB re $1 \mu \mathrm{Pa}$ RMS, 3 d averages) are also shown. Wind turbine sound data from Ingemansson Technology (2003) and ambient noise level data from Willie \& Geyer (1984). Wind turbine noise was recorded at a distance of $83 \mathrm{~m}$ distance with a Burns Electronics CR-3DC hydrophone connected via an Ingemansson S6 power supply to a Leuwen Measurement System Road Runner, sampling at $4000 \mathrm{~Hz}$ with 16 bit resolution. No antialiasing filter was used. For specifications on ambient noise recording conditions see Willie \& Geyer (1984)
2001, Ingemansson Technology 2003, Betke et al. 2004; see also Wahlberg \& Westerberg 2005 for review). Data on size and bottom depth of these wind turbines are summarized in Table 1. Most measurements have been made very close to a single wind turbine, so that any additive effects of other nearby turbines can be ignored. Even though the recorded wind turbines differ in size, bottom depth and foundation type, the genrated sounds have many features in common. The und intensity is generally dominated by a series of pure tones below $1 \mathrm{kHz}$, in most cases below $700 \mathrm{~Hz}$ (Fig. 3). The frequency content of the tones seems to be intimately linked to the mechanical properties of the wind turbine and does not seem to change with varying wind speed (Degn 2000, Ingemansson Technology 2003). From these data there seems to be only a weak relationship between the size of the wind turbine and the emitted sound intensity, but this contention may not be valid for large turbines of several megawatts (DEWI 2004).

The tonal noise from a wind turbine is created by vibrations in the gear-box inside the nacelle, and has both radial and tangential components (Degn 2000, Ingemansson Technology 2003, Knust et al. 2003, DEWI 2004). The vibrations are coupled to the water column and the seabed through the turbine foundations. The sound intensity may vary as a function of direction from the wind turbine, but this directionality has to our knowledge not been quantified or taken into account in any studies on wind turbine noise. Therefore it is not known how representative these measurements are for the maximum sound levels produced by wind turbines.

There is considerable variation in the reported noise levels from operating wind turbines (for review see Wahlberg \& Westerberg 2005). Such differences may in part 
be related to different wind speeds, recording conditions and sound radiation patterns, but there are nevertheless strong indications that some wind turbines make more underwater noise than others. By far the highest intensities were reported by Ingemansson Technology (2003) from the Utgrunden wind farm in the Baltic Sea. In Fig. 3, TOLs are shown for a measurement made at a distance of $83 \mathrm{~m}$ from the Utgrunden wind turbine, together with the power spectral density. From the spectrum it is clear that the turbine noise consists of narrow-band tones. Since these noise levels exceed the back-calculated source levels recorded in other studies by $10 \mathrm{~dB}$ or more (a 3 times higher sound pressure level) (Wahlberg \& Westerberg 2005), we have chosen them for evaluation of the impact on marine mammals as they represent the known worst case scenario compared to other reported noise profiles from operating turbine types. Consequently, we are if anything overestimating impact zones from operating turbines currently in use. However, it cannot be excluded that future, larger turbine constructions could be noisier (DEWI 2004), and this potential should be kept in mind in the following discussion. The strongest tonal component in Ingemansson Technology's (2003) recordings is around $180 \mathrm{~Hz}$ at a wind speed of $13 \mathrm{~m} \mathrm{~s}^{-1}$ (Fig. 3). At wind speeds of $8 \mathrm{~m} \mathrm{~s}^{-1}$ the dominant frequency is $60 \mathrm{~Hz}$, but the magnitude of this component is somewhat exaggerated due to the interference with $50 \mathrm{~Hz}$ electric noise during the measurements (H. Lindell, Ingemansson Technology, pers. comm.). Acoustic signals from wind farms other than that recorded by Ingemansson Technology (2003) could have less pronounced tonal components (see Wahlberg \& Westerberg 2005).

Ingemansson Technology (2003) also reported an increased sound level caused by increases in the number of active wind turbines in a wind farm. For these additive effects to take place, the sound source levels of the individual sources must be high enough to propagate to ranges at which interference might occur. The interference pattern created by the signals from several wind turbines will create a complex sound field. The received level in some locations may decrease due to negative interference with signals from different wind turbines. Depending on the geometry of the turbines, the received levels within the wind farm and nearby could increase with increasing number of wind turbines at a constant range from the measurement location, depending on the additive nature of the signals. These considerations and the few published attempts to model their effects, such as that by DEWI (2004), assume that the turbine noise is radiated omnidirectionally and may therefore not be very accurate.

To determine sound radiation from a wind turbine, it is not only necessary to know the source characteris- tics, but also the transmission-loss properties. In an acoustic free-field, sound intensity decreases by spherical spreading, as the instantaneous sound intensity is distributed evenly on an ever-expanding sphere as the sound propagates away from a point source. For such transmission-loss conditions, the decrease in sound intensity (in $\mathrm{dB}$ ) is $20 \log (\mathrm{r})+\alpha \mathrm{r}$, where $\mathrm{r}$ is the range in meters from the source to the receiver, and $\alpha$ is a frequency-dependent attenuation coefficient (Urick 1983). For the frequencies of interest here (below $1 \mathrm{kHz}$ ), the attenuation coefficient is less than $0.1 \mathrm{~dB} \mathrm{~km}^{-1}$ and is therefore negligible for all practical purposes. There are additional effects on the transmission loss through refraction caused by a spatially varying sound velocity, and there may also be effects of sound-scattering due to air bubbles and particles in the water column.

In shallow waters, the propagation conditions are normally far from those of an acoustic free-field. Sound is channelled through reflections at the surface and the bottom and refracted in a stratified water column (Kuperman \& Lynch 2004). The transmission loss can be reduced, sometimes all the way down towards cylindrical spreading, $10 \log (r)+\alpha r$, if the bottom and surface approach the properties of ideal reflectors (Medwin \& Clay 1998). However, transmission loss in shallow waters may also be significantly higher than expected from cylindrical spreading, because of refraction and scattering effects and acoustic interactions with the surface and sediment (Medwin \& Clay 1998). The latter effects involve the degree of wave agitation and the type of bottom sediments, which influence the coupling of the sound energy to the sea floor. Several generic models have been made to assess transmission loss in shallow waters, generating equations containing variables such as the frequency content of the signal, the acoustic properties of the sea floor, the sound velocity profile and the degree of surface agitation (Marsh \& Schulkin 1962, Piggott 1964, Wille \& Geyer 1984, DEWI 2004). If the information about the physical environment in which the sounds propagate is sufficiently detailed, there will often be a good agreement between the models and actual transmission-loss measurements. However, because the sound propagation is intimately linked to site-specific physical inhomogeneities that vary in time and space, there may be large differences in transmission losses between seemingly similar shallow-water habitats, and extrapolations between areas should thus be made with great caution. Also, transmission properties derived for a certain propagation path will often not allow for reliable extrapolations to larger ranges outside the area for which the given transmission loss was derived. Thus, the impact zones we estimate in the following should be evaluated in this light and the conclusions treated with appropriate caution. 
Transmission loss has been measured for sounds from pile-driving as well as sounds from operating wind turbines. In Figs. 4 \& 5, these measurements are compared to the traditional transmission-loss models of spherical and cylindrical spreading. It is important to realize that to compare the measurements with mod-

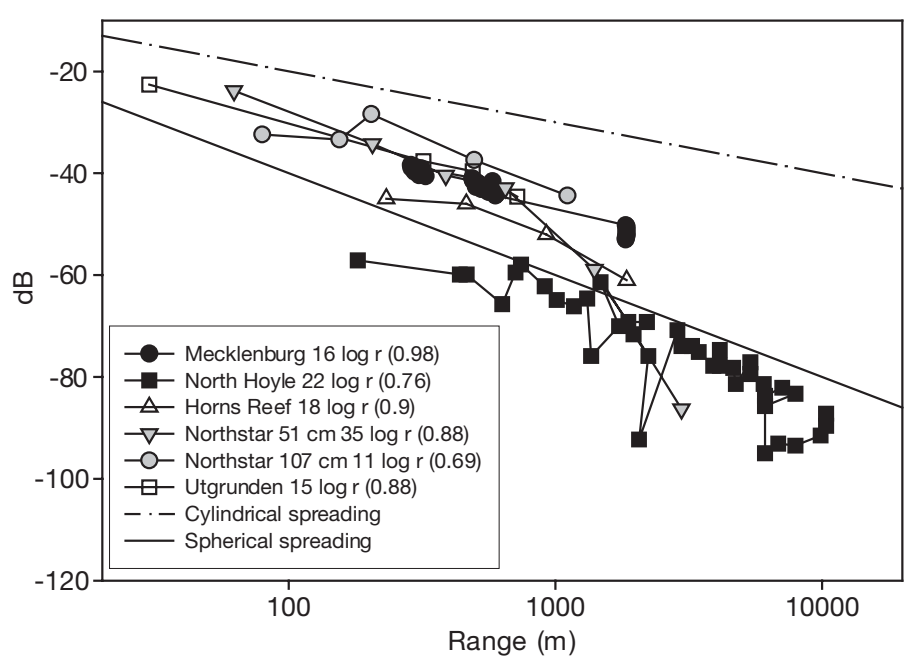

Fig. 4. Transmission loss during pile-driving of wind turbine foundations at 5 locations: Mecklenburg (from Betke et al. 2004); North Hoyle (from Nedwell et al. 2003); Horns Reef (from Anonymous 2002); Northstar (2 pipe diameters; Blackwell et al. 2004); Utgrunden (Degn 2000). Linear regression of transmission loss model TL $=x \log$ (range) is given (regression coefficient in parentheses). Peak sound levels are in decibels relative to back-calculated level at $1 \mathrm{~m}$ distance

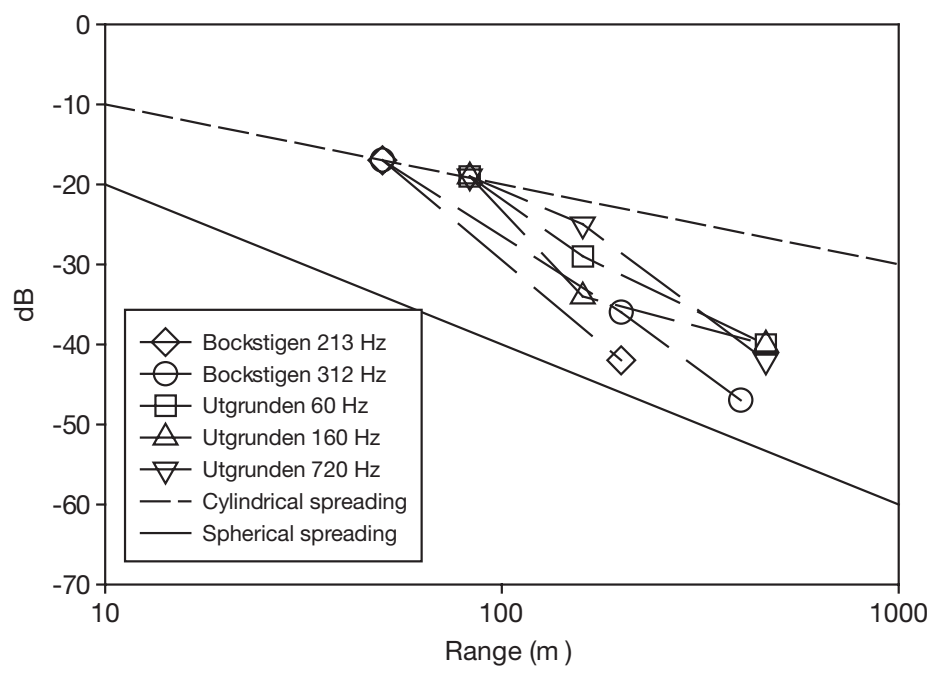

Fig. 5. Transmission loss recorded for wind turbines during operation at 2 locations in the Baltic Sea. Sound levels are RMS levels obtained from spectral levels analyzed by Fristedt et al. (2001: Bockstigen) and Ingemansson Technology (2003: Utgrunden) and are in decibels relative to back-calculated sound level at $1 \mathrm{~m}$ distance for that frequency els, the slope of the lines should be compared to the data series. For the transient impact sounds from piledriving, the available data suggest that transmission losses are close to spherical spreading up to ranges of more than $1 \mathrm{~km}$ (Fig. 4). At longer ranges the transmission loss may deviate considerably from what can be predicted by a simple spreading model; e.g. the data points for Horns Reef in Fig. 4 reflect a range-dependent attenuation much steeper than the $20 \mathrm{~dB}$ slope at longer ranges. Differences in the transmission-loss between different sites can be due to variations in the water depth and the acoustic properties of the bottom sediment.

For sounds recorded during wind turbine operation at the Utgrunden wind farm in the Baltic Sea, Ingemansson Technology (2003) reported that the transmission-loss was $13 \log (\mathrm{r})$. This transmission loss was deduced from measurements made at distances of between 83 and $500 \mathrm{~m}$ from the wind turbine, and was used to model the hearing ranges of fishes in regard to wind turbines by Wahlberg \& Westerberg (2005). However, when plotting the received levels of the individual frequency components as a function of range from Ingemansson Technology's (2003) study, a different picture emerges (Utgrunden data in present Fig. 5). Fristedt et al.'s (2001) data from a wind turbine in another location of the Baltic Sea provide a similar pattern of transmission losses dramatically exceeding both cylindrical and spherical spreading (Bockstigen data in present Fig. 5). Again, it is the slope of the 10 and $20 \log (\mathrm{r})$ models which should be compared to the slope in the data. The best fit approaches a spreading of about $30 \log (r)$ for both these data sets. Both Fristedt et al.'s (2001) and Ingemansson Technology's (2003) measurements were made in very shallow (6 to $18 \mathrm{~m}$ ) waters in the Baltic Sea. Sound can only propagate if the wavelength is less than or equal to 4 times the water depth (Urick 1983), meaning that frequencies below $60 \mathrm{~Hz}$ cannot propagate in $6 \mathrm{~m}$ of water. For softbottom sediments the cut-off frequency is even higher (Urick 1983). The $60 \mathrm{~Hz}$ data in Fig. 5 comprise the lowest frequency among the data, and also the component that experiences the highest transmission loss. In addition there may be complex interactions between acoustic and shear waves propagating through the sediment and the acoustic waves propagating through the water (Medwin \& Clay 1998). In situations with marked stratifications of salinity and temperature, such as can occur in the Baltic Sea, even more complicated transmission-loss patterns may apply (Kuperman \& Lynch 2004). Such mechanisms can explain the transmission loss in excess of both cylindrical and spherical spreading in Fig. 4. The caveat of these large fluctuations in transmission properties is that generalizations cannot be made and that site-specific mea- 
surements and modeling are required to understand the sound radiation patterns and propagation from each wind farm in question.

The apparent differences in propagation loss for continuous noise from operating wind turbines and the transient noise from the pile-driving activities in the same habitat may be related to the fact the transients and continuous tonal noise have very different interference patterns. For transient sounds, interference will first happen at long ranges, where the delay between direct and reflected paths will be of the same order of magnitude as the temporal extent of the signal. For continuous signals, interference will occur at much shorter ranges. Here, 'long' and 'short' should be viewed in relation to both the depth of the sound source as well as the depth and composition of the sea floor.

To conclude, sound transmission is of critical importance in evaluating effects of sounds on animals. The very commonly used, simple sound-propagation models have been derived for signal types and environmental circumstances that will often be very different from the complex shallow-water habitat in question. Therefore, physical measurements as well as more detailed modeling are needed for each specific construction site to reliably evaluate the effects of wind turbines on marine mammals over changing seasons and wind conditions. Since reliable modeling requires extensive measurements of environmental variables, it may in many cases be more productive to measure the transmission loss at different frequencies rather than to model it.

\section{REVIEW OF EFFECTS}

\section{Pile-driving}

Few studies have looked at the effects of pile-driving or other high-level, low-frequency impulsive sounds on marine mammals. Some studies have addressed the potential effects of sound pulses from airguns (reviews by McCauley et al. 2000 and Gordon et al. 2004), but these studies are often circumstantial and their results may not entirely apply to pile-driving. Airgun studies indicate that high-level impulsive sounds seem to have greater effect on cetaceans than pinnipeds (McCauley et al. 2000, Gordon et al. 2004).

A study on the effects of pile-driving on the ringed seals Phoca hispida at Northstar Island, Alaska, did not show dramatic reactions to underwater impulses with received levels of at least $150 \mathrm{~dB}$ re $1 \mu \mathrm{Pa}$ (RMS) (Blackwell et al. 2004). In contrast, observations on pile-driving of sheet piles in connection with one foundation at a large offshore wind farm in the western Baltic (Nysted wind farm) found a significant effect on the haul-out behavior of harbor seals (Edrén et al. 2004). Edrén et al.'s (2004) study, conducted over a period of $3 \mathrm{mo}$, showed a 10 to $60 \%$ reduction in the number of seals hauled-out on a sand bank approx. $10 \mathrm{~km}$ away during pile-driving, compared to periods with no pile-driving. Sound levels were not measured and no observations were made of seals in the water. It is thus not known whether the seals reacted to underwater noise by leaving the general area, or reacted to airborne sound by remaining in the water, but the reaction seemed to be short-term, as a concurrent series of aerial surveys did not show any decrease in the general abundance of seals during the construction period as a whole (Teilmann et al. 2004).

The responses of toothed whales to pile-driving sounds have been documented from construction of 2 offshore wind farms in Denmark. During construction of the Nysted offshore wind farm, the abundance of echolocating harbor porpoises was monitored by acoustic dataloggers and a significant decrease in detection of porpoise clicks relative to the pre-exposure baseline period was seen (Henriksen et al. 2003, Tougaard et al. 2005a). Reactions to pile-driving operations were documented by comparing the median time from the end of each pile-driving until the first recording of porpoise clicks with the median time between detections of porpoise click clusters in periods without pile-driving (clicks with interclick intervals less than $10 \mathrm{~min}$ were grouped in clusters and thus assigned to the same group or individual porpoise). Median waiting time increased from a range of 6 to $23 \mathrm{~h}$ to a range of 1 to $8 \mathrm{~d}$ (Tougaard et al. 2005a). This was true for all measuring positions, both inside the construction area and in a reference area $10 \mathrm{~km}$ from the construction site. It is noteworthy that the time between the first and the second encounter following the end of pile-driving was not significantly longer than the waiting time between encounters without pile-driving. This indicates a return to activity levels normal for the construction period as a whole some days after the pile-driving ceased. It is not known whether the absence of recorded clicks following a pile-driving event indicates that porpoises left the area or that they merely changed vocal behavior (ceased clicking). Although the former seems more likely, the important point is that both behaviors signify that animals were affected by the sounds and hence were within the zone of responsiveness.

Similar results were observed during pile-driving of 80 monopile foundations at Horns Reef offshore wind farm in Denmark, although the recovery to normal activity levels was much faster than for the Nysted wind farm, with median waiting times increasing from $<1 \mathrm{~h}$ to little more than $4 \mathrm{~h}$ (Tougaard et al. 2003). The same study also reported results from visual observa- 
tions of surface behavior of harbor porpoises, comparing days with pile-driving to days without. On days without pile-driving, the dominant behavior was nondirectional swimming (presumably associated with feeding), whereas the dominant activity on days with pile-driving was directional swimming (presumably associated with traveling) (Tougaard et al. 2003). Both acoustic and visual observations demonstrated significant effects at ranges up to $15 \mathrm{~km}$ from the construction site during pile-driving.

There are no published studies of the impact of piledriving on right whales, but there has been a series of studies on the impact of airguns on another balaenid mysticete, the bowhead whale Balaena mysticetus in Arctic waters. In the first such study, Richardson et al. (1986) found avoidance responses at levels above $160 \mathrm{~dB}$ re $1 \mu \mathrm{Pa}$ (unit unknown), but their study had relatively low capacity to detect responses at lower levels. Ljungblad et al. (1988) reported that some whales in 2 cases avoided airguns at ranges of 3.5 to $7.6 \mathrm{~km}$ with corresponding received levels of 142 to $158 \mathrm{~dB}$ re $1 \mu \mathrm{Pa}$ (RMS), and all whales observed in 4 more cases showed avoidance at ranges of 1.3 to $7.2 \mathrm{~km}$ with corresponding received levels of 122 to $178 \mathrm{~dB}$ re $1 \mu \mathrm{Pa}$ (RMS). Richardson et al. (1999) used a controlled experimental design to show that most migrating bowheads avoided airguns at a range of about $20 \mathrm{~km}$, at received levels ranging from $\sim 116$ to $135 \mathrm{~dB}$ re $1 \mu \mathrm{Pa}$ (RMS). These observations suggest that right whales may show avoidance responses to transient signals from the pile-driving above some $120 \mathrm{~dB}$ (RMS) re $1 \mu \mathrm{Pa}$. Thus, pile-driving has the potential to affect right whales over very large ranges, depending on the propagation conditions.

\section{Operating wind turbines}

No studies so far have directly measured the responses of marine mammals to noise from operating, offshore wind turbines. One study, however, examined the reactions of harbor porpoises and harbor seals to playbacks of simulated noise from an offshore turbine (Koschinski et al. 2003). Recordings from the wind farm (Degn 2000) were modified to simulate a $2 \mathrm{MW}$ turbine (roughly $10 \mathrm{~dB}$ added to source level from a smaller turbine in the range 40 to $100 \mathrm{~Hz}$ ) and played back through a J-13 underwater transducer in an area with a high abundance of harbor porpoises and harbor seals. Surfacings of porpoises and seals were tracked by a theodolite, and fewer surfacings than expected from baseline observations were seen in the range interval 0 to $60 \mathrm{~m}$ from the transducer for porpoises ( $p=0.04$ ) and up to $200 \mathrm{~m}$ from the transducer for seals $(p=0.008)$. It appears likely, however, that the proce- dure used by Koschinski et al. (2003) may have introduced high-frequency artifacts into the signal and that the porpoises and seals may have been responding to these artifacts rather than the low-frequency wind turbine noise intended for playback. In order to project the recorded signal at realistic levels, Koschinski et al. (2003) amplified the original recording by $26 \mathrm{~dB}$ to compensate for the spherical transmission loss from the transducer, and thus obtained the same sound pressure level as in the original recording at $20 \mathrm{~m}$ distance from the transducer. As the original noise recording from the wind turbine had no components above the background noise at frequencies above $500 \mathrm{~Hz}$ (Degn 2000) and the recording was not low-pass filtered before projection, the projected signal contained not only turbine noise but would also have contained amplified background noise from the original recording. This noise extends up to at least $8 \mathrm{kHz}$ (Koschinski et al. 2003), where it has a TOL of $113 \mathrm{~dB}$ re $1 \mu \mathrm{Pa}$, well above both ambient noise TOL and hearing thresholds of porpoises and seals (Fig. 1). As the experiments were conducted under calm conditions (Sea State 2 or below) ambient noise levels were likely to be low, which would have made the high-frequency noise audible to both porpoises and seals at considerable ranges. Either way, Koschinski et al.'s (2003) study showed that the responses, if any, occurred within a 60 to $200 \mathrm{~m}$ perimeter around the sound source, reinforcing the conclusion that the impact zone for turbine noise is small for both porpoises and seals.

Several ongoing studies at Nysted and Horns Reef offshore wind farms are addressing the possible effects of turbines in operation (Teilmann et al. 2004, Tougaard et al. 2005a,b), but these studies are looking at the general effects of the operating turbines and are not targeted specifically at the effects of underwater noise.

There have not been any studies on the impact of turbine noise on baleen whales. The noise from turbines is stationary, like some other marine construction activities, and has TOLs relatively similar to the continuous noise from other industrial activities such as dredging and production platforms. Dredging and drilling operations had a maximum TOL near the $100 \mathrm{~Hz}$ range at levels near $160 \mathrm{~dB}$ (RMS) re $1 \mu \mathrm{Pa}$ (Richardson et al. 1995, their Fig. 6.16), similar signals but with higher levels than the windmill data presented in the present paper. More recently, Nowacek et al. (2004) documented strong avoidance reponses of North Atlantic right whales Eubalaena glacialis to tonal signals at received levels ranging from 134 to $148 \mathrm{~dB}$ (RMS) re $1 \mu \mathrm{Pa}$. Richardson et al. (1995) summarized results of drillship and dredge-noise playbacks to bowhead whales, and concluded that these balaenid whales may react at TOLs as low as $110 \mathrm{~dB}$ 
(RMS) re $1 \mu \mathrm{Pa}$. It seems therefore that northern right whales may respond to noise from operating turbines at ranges up to a few kilometers in a quiet habitat. The available data on the effects of noise from operating wind turbines are sparse, but suggest that behavioral effects, if any, are likely to be minor and to occur close to the turbines.

\section{MODELING OF IMPACT ZONES AND MASKING BY OTHER NOISE SOURCES}

\section{Pile-driving}

The range of the impact zones for sounds from piledriving operations depends on the source level of the sound source, the transmission-loss properties of the habitat, and the hearing abilities of the animal. Here we investigate the ranges of the impact zones using conservative assessments of these parameters. We use the highest reported sound pressure levels of piledriving sounds, the lowest measured transmission loss for pile-driving sounds $(16 \log [\mathrm{r}]+\alpha \mathrm{r}$ from the data in Fig. 4), the lowest ambient noise levels in Fig. 1, and the most conservative acoustic threshold estimates for the animals. Thus, the ranges are probably overestimated, but in the face of uncertainty we feel a conservative approach prudent.

The highest intensities recorded from a pile-driver gave a received level of $200 \mathrm{~dB}$ re $1 \mu \mathrm{Pa}$ (RMS) at a range of $100 \mathrm{~m}$ (Anonymous 2001). The most powerful pile-driving signals analyzed here were about $10 \mathrm{~ms}$ long, had a centroid (mean) frequency of around $380 \mathrm{~Hz}$, and an RMS bandwidth (providing the frequency spread around the centroid) of $720 \mathrm{~Hz}$. The bottlenose dolphin and harbor porpoise have a hearing threshold higher than $120 \mathrm{~dB}$ re $1 \mu \mathrm{Pa}$ at $200 \mathrm{~Hz}$, which is well above the background noise levels in Fig. 1. This gives a signal-to-noise ratio of around $80 \mathrm{~dB}$ for the pile-driving signal at a range of $100 \mathrm{~m}$. Assuming a transmission loss of $16 \log (\mathrm{r})+\alpha \mathrm{r}$, the pile-driving signal would decrease to threshold at a range of more than $1000 \mathrm{~km}$. For the harbor seal and the northern right whale, with more acute low-frequency hearing abilities, the signal-to-noise ratio is probably limited by ambient noise rather than the hearing threshold. As the pile-driving signal covers several TOLs, it seems more appropriate to compare the signal level with the noise integrated over the RMS bandwidth of the signal ( $720 \mathrm{~Hz}$ for the waveform used here). This would mean that the effective masking noise level is about $9 \mathrm{~dB}$ higher than the TOL for detection of the pile-driving signal, i.e. a little less than $110 \mathrm{~dB}$ re $1 \mu \mathrm{Pa}$ rms (see Fig. 1). This would mean that the signal-to-noise ratio is $90 \mathrm{~dB}$ at $100 \mathrm{~m}$ distance from the source, correspond- ing to an estimated zone of audibility of several thousand kilometers when using $16 \log (\mathrm{r})$ transmission loss (Fig. 4). Such long detection distances are not necessarily realistic, however, as the signal will experience additional attenuation due to sound-scattering and refraction processes, and the propagation criteria may not apply beyond the area for which they were derived. Nevertheless, the calculated ranges clearly indicate that pile-driving sounds are audible to all the marine mammals treated here at very long ranges of more than $100 \mathrm{~km}$, and possibly up to more than a thousand kilometers.

Due to the short duration and low duty cycle (duration of individual signals relative to repetition interval of signals) of pile-driving sounds, these are not likely to introduce significant masking problems for the animals. The zone of masking may therefore have little meaning for pile-driving sounds. However, because of the high received levels from such sounds it cannot be ruled out that reception of significant signals (prey or conspecifics) may be impaired not by masking in a strict sense, but by related effects, such as neural or muscular accommodation or simply distraction by the high sound pressures.

The zone of behavioral responsiveness may differ significantly between the 4 species in question. As noted above, data on the reaction of marine mammals to pile-driving operations are very limited, calling for more dedicated studies. For harbor porpoises there is evidence that they may react to pile-driving noise at distances of at least 10 to $15 \mathrm{~km}$ (Tougaard et al. 2003, 2005a). For bottlenose dolphins, little or no data on this issue exist. For harbor seals, the only relevant study available concerns a different species, the ringed seal Phoca hispida. That study could not detect behavioral reactions at received levels lower than $150 \mathrm{~dB}$ re $1 \mu \mathrm{Pa}$ (RMS) (Blackwell et al. 2004). For large pile-driving operations, received levels of $150 \mathrm{~dB}$ re $1 \mu \mathrm{Pa}$ or higher can be expected at ranges of many kilometers. Therefore it seems reasonable in the light of limited behavioral data and the propagation considerations to conclude that pile-driving operations have the potential to cause disruption of normal behavior in marine mammals over a very large area at ranges of many kilometers.

Pending the development of new criteria for acoustic effects, and following current National Marine and Fisheries Sciences regulations (NMFS 2003), we will define the zone of injury for the cetaceans to extend to a range where the sound level has dropped to $180 \mathrm{~dB}$ re $1 \mu \mathrm{Pa}$ (RMS) and $190 \mathrm{~dB}$ re $\mu \mathrm{Pa}$ (RMS) for pinnipeds. The use of RMS measures is problematic for transient signals (Madsen 2005), but there is no consensus on more appropriate alternatives at present. For the most conservative transmission loss depicted in Fig. 4 and 
for a pile-driver generating $200 \mathrm{~dB}$ re $1 \mu \mathrm{Pa}$ (RMS) at $100 \mathrm{~m}$ range, this safety level translates to a range of about $2 \mathrm{~km}$. For harbor seals, if we use the NFMS recommended threshold of $190 \mathrm{~dB}$ re $1 \mu \mathrm{Pa}$ (RMS), the estimated zone of injury is around $700 \mathrm{~m}$. If effective, the use of deterrence devices as a pre-exposure mitigation measure, as used both at Horns Reef and Nysted offshore wind farms (Henriksen et al. 2003, Tougaard et al. 2003), may reduce the risk of exposing nearby animals to impairing sound pressure levels, but will not change the fact that animals in a large area are likely to be affected behaviorally.

\section{Operating wind turbines}

When evaluating the impact of noise from operating wind turbines it is important to realize that the noise levels they emit are low both on a relative and absolute scale. There are no direct measurements to suggest that source levels of the pure-tone noise components from an operating wind turbine exceed $145 \mathrm{~dB}$ re $1 \mu \mathrm{Pa}$ (RMS), and such levels are the absolute highest backcalculated from any reported measurements (Wahlberg \& Westerberg 2005). All measurements suggest that the received levels drop to $<120 \mathrm{~dB}$ re $1 \mu \mathrm{Pa}$ (RMS) at $100 \mathrm{~m}$, and that the levels propagating in the water column beyond this point consequently will be low irrespective of the propagation conditions. As evident from the section 'Marine mammal hearing and noise', the relevant groups of marine mammals in this study can be divided into 2 groups: those, such as the small toothed whales, that have poor low-frequency hearing and are likely to be limited by hearing threshold; and those, such as the harbor seal and the northern right whale, that have sufficiently good low-frequency hearing to be limited by ambient noise. The most extensive zone of possible impact is the zone of audibility. This zone is defined as the range at which a marine mammal can barely detect the emitted noise. The audiograms in Fig. 1 show that the hearing threshold for both Phocoena phocoena and Tursiops truncatus is higher than $122 \mathrm{~dB}$ re $1 \mu \mathrm{Pa}$ (RMS) at a frequency of $180 \mathrm{~Hz}$, the frequency at which the wind turbines generate the highest noise levels. This component of turbine noise is thus unlikely to be audible to $P$. phocoena and T. truncatus at distances beyond $100 \mathrm{~m}$. As the hearing sensitivity of both species increases by roughly $6 \mathrm{~dB}$ per doubling of frequency for low frequencies, the smaller peak at $700 \mathrm{~Hz}$ is about $10 \mathrm{~dB}$ above the background noise at $83 \mathrm{~m}$ and should be clearly audible. Depending on propagation conditions (see below), this translates into a maximal detection distance somewhere between 200 and $500 \mathrm{~m}$. There is accordingly no reason to believe that $P$. phocoena and $T$. truncatus can hear even the noisiest of the wind turbines currently in use at a range of more than a few hundred meters. Thus, the impact on small toothed whales of known noise levels and spectral properties from operating wind turbines is likely to be minor because of their poor low-frequency hearing-capabilities.

A reservation to this conclusion is that the sound measurements made until now have not taken into account any possible directional effects (i.e. areas in different directions from the wind turbine than those in which the acoustic measurements were made could experience higher received levels), nor that the cumulative effects of an array of turbines close together may lead to significantly higher received levels at long ranges. Another reservation is that larger and potentially noisier turbines (DEWI 2004) may change this picture radically, which in turn calls for measurements of future larger turbines.

For the low-frequency hearing-specialists, in this case represented by the harbor seal and the northern right whale, ambient noise is likely to be the limiting factor for detection of the noise components radiated from the wind turbines. The largest difference between the highest turbine noise TOL and ambient noise TOL at the same frequencies occurs at wind speeds of $13 \mathrm{~m} \mathrm{~s}^{-1}$. In this situation, the recorded wind mill noise level at a range of $83 \mathrm{~m}$ is $122 \mathrm{~dB}$ re $1 \mu \mathrm{Pa}$ (RMS) at $180 \mathrm{~Hz}$ and the measured ambient noise TOL at a center frequency of $160 \mathrm{~Hz}$ (the closest ambient noise measurement made to $180 \mathrm{~Hz}$ ) is $90 \mathrm{~dB}$ re $1 \mu \mathrm{Pa}$ (RMS). There is accordingly $32 \mathrm{~dB}$ of signal-to-noise ratio (SNR) available for transmission-loss if detection is possible at an SNR of $0 \mathrm{~dB}$. The transmission loss of 13log(r) reported by Ingemansson Technology (2003) would predict that the noise may propagate some $20 \mathrm{~km}$ before being reduced to the ambient noise TOL of $90 \mathrm{~dB}$ re $1 \mu \mathrm{Pa}$ (RMS). Thus, the zone of audibility for the low-frequency hearing specialists may be $>10 \mathrm{~km}$ under ideal conditions using this propagation model and the ambient noise levels and high turbine levels measured by Ingemansson Technology (2003). Small increases in the ambient noise levels or different propagation conditions can change this range significantly. For example, if $30 \log (\mathrm{r})$ propagation conditions apply as indicated previously, the range of audibility will be reduced to $1.3 \mathrm{~km}$, all other factors being equal.

Several natural factors, such as surf noise and rain, may increase the ambient noise TOL significantly by 6 to $10 \mathrm{~dB}$ in some areas (Urick 1983), which in turn will reduce the range of audibility 2 to 6 times, depending on propagation conditions. The zone of audibility of $>10 \mathrm{~km}$ should therefore be viewed as a theoretical maximum, and it must be emphasized that the actual distance that a harbor seal or a baleen whale can hear an operating wind turbine is probably significantly less. 
The known noise levels emitted by operating wind turbines are low by any comparative standard (Richardson et al. 1995), and it therefore seems relevant to evaluate the noise impact of operating turbines relative to the noise levels of other anthropogenic noise sources in shallow-water habitats. One of the most prominent man-made sources of underwater noise is motorized shipping (Urick 1983). Modern cargo ships at high cruising speeds have TOL source levels around $175 \mathrm{~dB}$ re $1 \mu \mathrm{Pa}$ (RMS) in the frequency range between 30 and $300 \mathrm{~Hz}$ (NRC 2000, Arveson \& Venditis 2001). Consequently, the source TOL of a cargo ship is at least $30 \mathrm{~dB}$ (30 times) higher than the highest of the estimated source TOL of the noisiest wind turbines measured so far (Ingemansson Technology 2003). This implies that the presence of a cargo ship in an area with wind farms will mask the noises from the turbines at considerable ranges. Such ranges critically depend on the propagation properties of the habitat. Fig. 6 demonstrates the effect of a modern cargo ship moving at different distances from a marine mammal close to an operating wind turbine. Under $13 \log (\mathrm{r})$ propagation conditions a marine mammal $100 \mathrm{~m}$ from an operating wind turbine receives TOL noise levels equal to those produced by a cargo ship at a distance of $14 \mathrm{~km}$ from the animal. If the marine mammal is $1000 \mathrm{~m}$ from the wind turbine, then the noise TOLs from the turbine will be equaled by those of a cargo ship at a distance of $>100 \mathrm{~km}$. Hence, for low-loss propagation conditions, the presence of a

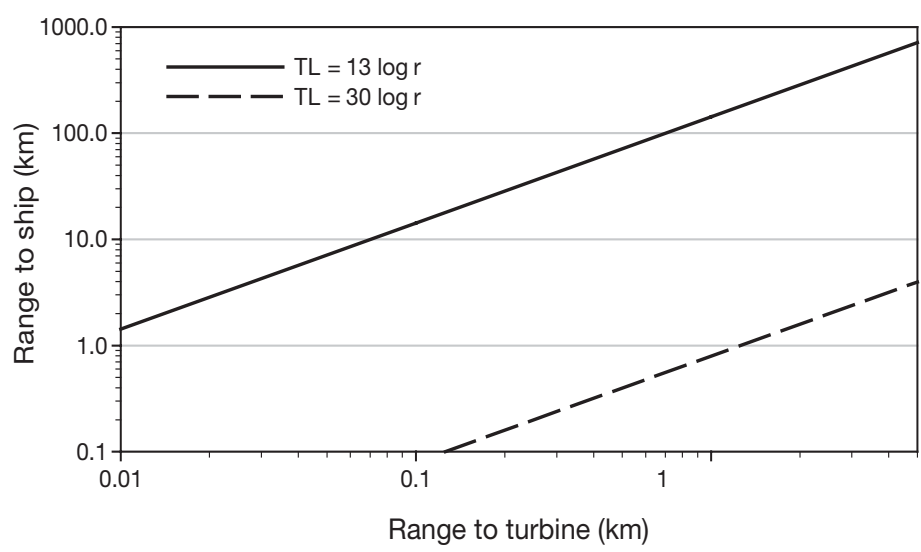

Fig. 6. Range at which third-octave noise level at a center frequency of $160 \mathrm{~Hz}$ radiates from a large cargo ship equals the third-octave noise level at $160 \mathrm{~Hz}$ from a wind turbine. Continuous line: range calculated from a transmission loss of $13 \log (\mathrm{r})$; dashed line: $\operatorname{loss}$ from $30 \log (\mathrm{r})$. With transmission loss of $13 \log (\mathrm{r})$, TOL noise received by marine mammal $100 \mathrm{~m}$ from a wind turbine will equal received TOL noise from a cargo ship at $14 \mathrm{~km}$ distance; with a transmission loss of $30 \log (\mathrm{r})$, back-calculated source level of turbine roughly equals that of the ship, and the marine mammal would need to be at the same distance from ship and turbine to receive equal TOLs cargo ship at ranges of tens of kilometers will swamp the received noise from an operating wind turbine, unless the exposed marine mammal with good lowfrequency hearing is very close to the turbine.

This scenario emphasizes that modern cargo ships contribute significantly to the ambient noise levels in the oceans, much more so than operating wind turbines. This does not imply that the noise from wind turbines is negligible in habitats with low transmissionlosses, but that any discussion of long-range effects of wind turbine noise on marine mammals is only relevant for areas with no or very little motorized shipping. If the transmission loss conditions are $30 \log (\mathrm{r})$, then the situation is changed. Under such circumstances, the back-calculated source TOL of the turbine will be slightly higher than the measured source TOL of the cargo ship, and the animal must be closer to the cargo ship than the wind turbine to experience an equal received TOL from the 2 sources. However, under $30 \log (\mathrm{r})$ transmission conditions, the zone of audibility for the low-frequency hearing-specialists around a wind turbine will be on the order of $1 \mathrm{~km}$, so the interference effects of noise from passing ships is relevant only close to the source. As stated at the end of this subsection, it is unlikely that the actual noise level close to the turbine will ever be as high as the source level back-calculated with $30 \log (\mathrm{r})$.

The zone of masking is simple to define, yet in practice it is not easy to estimate its extent. For masking to be meaningful to an animal, the masking noise must raise the detection threshold of a sound signal important to that animal. If an animal listens for more than 1 signal, as all animals probably do, then multiple zones of masking must exist. Masking occurs whenever sufficient noise is present in or close to the frequency band of the relevant signal. The first step in estimating masking potential is thus to establish whether there is an overlap in the frequency bands of the noise and sounds relevant for the animal. Harbor porpoises use ultrasonic signals with little energy below $100 \mathrm{kHz}$ (Møhl \& Andersen 1973). As the turbine noise does not elevate the noise level at these frequencies, there is thus no potential for turbine noise to mask the reception of porpoise clicks. The zone of masking for porpoises in case of noise from operating turbines is thus zero, and the same is probably the case for dolphins. Even though dolphins use whistles to communicate, there is little energy in these signals below $1 \mathrm{kHz}$, and they do not overlap with the frequencies of the turbine sounds. We cannot exclude that the animals passively use ambient sounds at low frequencies that can be masked by turbine noise, but lack of data on this possibility prevents detailed assessment.

Harbor seals produce underwater vocalization at frequencies down to $100 \mathrm{~Hz}$ (Bjørgesæeter et al. 2004), and 
masking cannot thus be ruled out on the basis of lack of frequency overlap. The turbine sounds have sharp spectral peaks, however, and consist of several puretone components. Pure tones have a very poor masking ability (Green 1969, Zwicker \& Schorn 1978), unless there is an exact match with the frequency of interest. Bearded seals Erignathus barbatus seem to shift the frequency of their tonal calls to reduce the masking effects of tonal noise, and other seals may have similar compensation mechanisms (Terhune 1999). As the underwater sounds of seals are more broadband than turbine noises and, in most cases, have significant energy above the frequencies of turbine noise, the masking power of the latter is likely to be minor. The zone of masking for seals in the case of turbine noise can thus probably be assumed to be small for all practical purposes. Baleen whales use low-frequency sounds for communication, and species like the right whale use tonal signals in the frequency range from roughly 20 to $1000 \mathrm{~Hz}$, with broadband source levels ranging from 137 to $162 \mathrm{~dB}$ (RMS) re $1 \mu \mathrm{Pa}$ at $1 \mathrm{~m}$ (Parks \& Tyack 2005). Thus, in the case of the right whale and other baleen whales, turbine noise may have a masking effect on communication over distances of some kilometers in a quiet habitat with no motorized shipping.

Turbine sound levels are so low that discussions of physical damage arising from them are largely hypothetical. Even taking a spreading loss of 30log (r) close to the turbine would result in an artificially high broadband sound-source level of around $180 \mathrm{~dB}$ re $1 \mu \mathrm{Pa}$ (RMS) for the noisiest of the turbine studied (Ingemansson Technology 2003), and with a foundation diameter of around $8 \mathrm{~m}$ this theoretical level would be back-calculated to a point inside the turbine. Since the radiating turbine tower is not a point source, it is unlikely that the $180 \mathrm{~dB}$ re $1 \mu \mathrm{Pa}$ RMS back-calculated from measurements at $80 \mathrm{~m}$ distance under the worst of propagation conditions is realized at any point in the water column. We do, however, suggest that such assertions be tested experimentally in the near-field of operating turbines.

Impairing effects of noise exposure at lower levels have recently been demonstrated for dolphins, for which experiments on long-term exposure to noise demonstrated temporary TTS effects at $160 \mathrm{~dB}$ re $1 \mu \mathrm{Pa}$ (RMS) (Nachtigall et al. 2004). Actual sound pressures up to this level could potentially (in the worst of circumstances) be found within tens of meters of the turbine, and it can be argued that an animal that remains close to the turbine for a prolonged period of time would risk temporary threshold shifts. The practical relevance of such a zone, calculated from worst case assumptions, appears to be very low, however, and it seems reasonable to conclude that the zone of injury is essentially zero for all 4 marine mammal species discussed herein. Again, such assessment is based on noise levels for turbines already in operation and not for future, potentially noisier, turbines.

\section{CONCLUSIONS AND FUTURE WORK}

Knowledge of the effects on marine mammals of constructing and operating offshore wind farms is limited. The underlying issue is the lack of appropriate measures and data on behavioral reactions of the exposed animals and the short- and long-term consequences of exposure. On the other hand, this review has made clear that the level of impact must be separated into (1) construction activities, such as pile-driving, where there is indeed reason for concern, and (2) operational effects, which in most cases are likely to be small, especially compared to impacts from other more common anthropogenic and natural noise sources. There are several important unresolved issues regarding the propagation of sound, whether pile-driving impulses or turbine noise, and propagation conditions for one area will rarely be applicable to other areas. We recommend actual measurements of frequencydependent sound-propagation for both continuous and transient sounds at each wind farm site. However, such measurements will not enable reliable assessment of impacts unless they are coupled to a better knowledge of the effects (if any) of these sounds on the animals, and at what received levels they occur.

With respect to the known noise levels of turbines presently in operation, there seems to be little reason to believe they have a significant impact on marine mammals in general. Elaborate investigations on the propagation of low-level sound from operating wind turbines may therefore not be justified, if behavioral studies confirm that the range of received levels more than $100 \mathrm{~m}$ from the turbine do not alter the behavior of the marine mammal species in question. All data and modeling suggest that there is little ground for concern for small toothed whales in this respect, but it seems relevant to explore the effects of 30 to $200 \mathrm{~Hz}$ tones on representative species with better lowfrequency hearing (such as seals and shallow-water baleen whales) via carefully designed playback studies at received levels between 110 and $140 \mathrm{~dB}$ re $1 \mu \mathrm{Pa}$ (RMS). It should be strongly emphasized, however, that the lack of serious concern expressed herein is based on measurements from turbines presently in operation. These data are not entirely adequate, and may not be representative of future, larger, and potentially significantly noisier turbines (DEWI 2004). It is important to address, experimentally, possible directional and additive effects in the acoustic radiation pat- 
terns from those wind turbines already in operation, and to quantify noise radiated from future generations of larger turbines. We recommend that operational guidelines for wind farms include maximum noise levels that are lower or do not exceed the measured lowfrequency levels (TOLs $<110 \mathrm{~dB}$ re $1 \mu \mathrm{Pa}$ RMS at $100 \mathrm{~m}$ ) reported for most turbines in operation at present. If such guidelines are followed, the conclusions of this paper should still be valid for future wind farms.

In our view, the analysis of environmental impacts should be broadened to include effects of noise from construction as a whole, and not limited to the effects of pile-driving. Large-scale operations such as the assembly of a wind farm involve many activities, some of which generate noise at levels sufficient to impact the behavior of marine mammals and impair hearing at considerable ranges. Such activities include seismic (with airguns) and bottom (with sonar) topography explorations prior to construction, dredging, deposition of gravel, and excavations in bedrock with explosives. The potential effects of pile-driving and other highlevel impulses from construction activities are more detrimental to all species and cover much larger ranges than the noise from operating wind turbines. The ranges at which animals may be exposed to received levels above the sound pressure thresholds for the impact zones considered here are orders of magnitude larger for pile-driving than for turbine noise. All available data suggest that the impact of pile-driving is significant at long ranges, and that further data on dose-response and mitigation measures are needed along with reliable propagation models for each habitat. Mitigation during pile-driving at Horns Reef and Nysted offshore wind farms consisted of deployment of acoustic deterrence and harassment devices (porpoise pingers and seal-scarers) prior to each pile-driving operation. This type of mitigation may significantly reduce the risk of exposing animals to detrimental sound levels by deterring them from the zone of injury prior to the actual pile-driving. However, deterrence devices (or ramp-up procedures) do not reduce the size of any of the zones of impact. Since especially the zone of responsiveness may be of considerable size, there is still likely to be a significant impact on the animals behaviorally, although the risk of direct physical injury is reduced. Mitigation measures that include reduction of the sound pressure levels radiated into the water column have the advantage of effectively reducing the size of all zones of impact. No matter what the sound source, a reduction in the effective source levels by $6 \mathrm{~dB}$ will reduce the volume of water exposed to a given sound pressure by 4 to 8 times, depending on the propagation conditions. Bubble curtains have a promising potential for significantly reducing the zones of impact from pile-driving (Rodkin \& Reyff
2004), and tests and implementation of such mitigative measures should be encouraged.

Construction activities and the associated noise production involve short-term exposure, limited to a period of months rather than years, as is the case for the operation of wind turbines. When assessing the effects of construction, it is thus important to investigate not only whether there is an impact on behavior of the animals, but also what this impact means in terms of loss of fitness for the animals. A given activity may produce a complete, but temporary, displacement from an area, but if the animals all return to the area shortly afterwards with no hearing impairment, the actual impact on the population may be small. Whether or not the displacement can be classified as a minor impact depends strongly on local circumstances and the biology of the animal in question, for instance a species could partly or completely be kept away from an important, seasonal food source at a critical point in its breeding cycle. At the present pace in the development of offshore wind farms, cumulative effects from construction are unlikely to be of concern, but may become relevant if and when some of the proposed plans for very large offshore wind farms are realized. For example, if the current plans for the German Bight area in the North Sea are realized (Koschinski et al. 2003), this could involve construction activities at several locations in this area simultaneously every summer for the next decade, and the impact would therefore no longer be short-term. Studies on habitat-use by the relevant marine mammals in areas of wind farm construction and operation should be carried out.

Acknowledgements. We thank C. Boesen, O. D. Henriksen, S. Koschinski, J. Kjær, J. Lynch, B. Møhl, B. K. Nielsen, J. Teilmann, E. Terray, F. Thomsen, A. Villadsgaard and H. Westerberg for helpful discussions and/or constructive critique on earlier versions of the manuscript. J. Reyff of Illingworth \& Rodkin kindly provided the waveform of a pile-driving transient. This study was funded by Massachusetts Technology Collaborative grant \# OWEC-05-02. M.W. was funded by the Carlsberg Foundation. The work of K.L. was partially supported by the German Federal Agency for Nature Conservation through the German Ministry for the Environment. This is contribution number 11332 of the Woods Hole Oceanographic Institution.

\section{LITERATURE CITED}

Anonymous (2001) San Francisco-Oakland Bay Bridge, East Span Seismic Safety Project, Pile Installation Demonstration Project, Fisheries Impact Assessment. PIDP EA 01208, Caltrans contract 04A0148, Task Order 205.10.90, PIDP 04-ALA-80-0.0/0.5, p 1-32

Anonymous (2002) Horns Reef - noise in the sea during piledriving of a turbine foundation. Report from Tech-Wise A/S, Fredericia, p 1-49 (in Danish)

Arveson PT, Vendittis DJ (2000) Radiated noise characteristics of a modern cargo ship. J Acoust Soc Am 107:118-129 
Au WWL (1993) The sonar of dolphins. Springer-Verlag, New York

$\mathrm{Au}$ WWL, Moore PWB (1990) Critical ratio and critical bandwidth for the Atlantic bottlenose dolphin. J Acoust Soc Am 88:1635-1638

$\mathrm{Au}$ WWL, Ford JK, Horne JK, Allman KAN (2004) Echolocation signals of free-ranging killer whales (Orcinus orca) and modeling of foraging for Chinook salmon (Oncorhyncus tshawytscha). J Acoust Soc Am 115:901-909

Betke K, Schultz-von Glahn M, Matuschek R (2004) Underwater noise emissions from offshore wind turbines. Proc CFA/DAGA 2004, Strasbourg

Bjørgesæter A, Ugland KI, Bjørge A (2004) Geographic variation and acoustic structure of the underwater vocalization of harbor seal (Phoca vitulina) in Norway, Sweden and Scotland. J Acoust Soc Am 116:2459-2468

Blackwell SB, Lawson JW, Williams JT (2004) Tolerance by ringed seals (Phoca hispida) to impact pipe-driving and construction sounds at an oil production island. J Acoust Soc Am 115:2346-2357

Degn U (2000) Offshore wind turbines-VVM, underwater noise measurements, analysis, and predictions. Ødegaard \& Danneskiold-Samsøe A/S, Rep No 00-792 rev. 1. p 1-230 (also available at: http://uk.nystedhavmoellepark.dk)

DEWI (Deutsches Windenergie-Institut) (2004) Standardverfahren zur Ermittlung und Bewertung der Belastung der Meeresumwelt durch die Schallimmission von OffshoreWindenergieanlagen. Forschungsvorhaben 0327528A. Deutsches Windenergie-Institut, Wilhelmshaven

Edrén SME, Teilmann J, Dietz R, Carstensen J (2004) Effect from the construction of Nysted offshore wind farm on seals in Rødsand seal sanctuary based on remote video monitoring. Technical report to Energy E2 A/S. National Environmental Research Institute, Roskilde

Erbe C, Farmer DM (1998) Masked hearing thresholds of a beluga whale (Delphinapterus leucas) in icebreaker noise. Deep-Sea Res II 45:1373-1388

Finneran JJ, Schlundt CE, Carder DA, Ridgway SH (2002) Auditory filter shapes for the bottlenose dolphin (Tursiops truncatus) and the white whale (Delphinapterus leucas) derived with notched noise. J Acoust Soc Am 112:322-328

Fristedt T, Morén P, Söderberg P (2001) Acoustic and electromagnetic noise induced by windmills -implications for underwater surveillance systems: pilot study. FOI-R-0233SE. FOI, Swedish Defence Research Agency, Stockholm

Gordon J, Gillespie D, Potter J, Frantzis A, Simmonds M, Swift R, Thompson D (2004) The effects of seismic surveys on marine mammals. Mar Technol Soc J 37:16-34

Green DM (1969) Masking with continuous and pulsed sinusoids. J Acoust Soc Am 46:939-946

Henriksen OD (2001) Noise from offshore wind turbineseffects on porpoises and seals. MSc thesis, University of Southern Denmark, Odense (in Danish)

Henriksen OD, Teilmann J, Carstensen J (2003) Effects of the Nysted offshore wind farm construction on harbour porpoises - the 2002 annual status report for the acoustic TPOD monitoring programme. National Environmental Research Institute, Roskilde

Ingemansson Technology AB (2003) Utgrunden offshore wind farm-measurements of underwater noise. Report 11-0032903012700. Ingemansson Technology A/S, Gothenburg

Jefferson TA, Curry BE (1996) Acoustic methods of reducing or eliminating marine mammal-fishery interactions: do they work? Ocean Coast Manag 31:41-70

Johnson CS (1967) Sound detection thresholds in marine mammals. In: Tavolga WN (ed) Marine Bioacoustics II. Pergamon, Oxford, p 247-260
Johnson CS, McManus MW, Skaar D (1989) Masked tonal hearing thresholds in the beluga whale. J Acoust Soc Am 85:2651-2654

Kastak D, Schusterman RJ (1998) Low-frequency amphibious hearing in pinnipeds: methods, measurements, noise, and ecology. J Acoust Soc Am 103:2216-2228

Kastak D, Schusterman RJ (1999) Underwater temporary threshold shift induced by octave-band noise in three species of pinniped. J Acoust Soc Am 106:1142-1148

Kastelein RA, Bunskoek P, Hagedoorn M, Au WWL, de Haan D (2002) Audiogram of a harbor porpoise (Phocoena phocoena) measured with narrow-band frequency modulated signals. J Acoust Soc Am 112:334-344

Ketten DR (2000) Cetacean ears. In: Au WWL, Popper AN, Fay RR (eds) Hearing in whales and dolphins. SpringerVerlag, New York, p 43-108

Knust R, Dalhoff P, Gabriel J, Heuers J, Hüppop O, Wendelin $H$ (2004) Untersuchungen zur Vermeidung und Verminderung von Belastungen der Meeresumwelt durch Offshore-Windenergieanlagen in küstenfernen Bereich der Nord- und Ostsee. 62/03. Umweltbundesamt, Büsum

Koschinski S, Culik BM, Henriksen OD, Tregenza N, Ellis G, Jansen C, Kathe C (2003) Behavioural reactions of free-ranging porpoises and seals to the noise of a simulated $2 \mathrm{MW}$ windpower generator. Mar Ecol Prog Ser 265:263-273

Kuperman WA, Lynch JF (2004) Shallow water acoustics. Phys Today Oct:55-61

Ljungblad DK, Würsig B, Swartz SL, Keene JM (1988) Observations on the behavioral responses of bowhead whales (Balaena mysticetus) to active geophysical vessels in the Alaskan Beaufort Sea. Arctic 41:183-194

Madsen PT (2005) Marine mammals and noise: problems with root-mean-square sound pressure safety levels for transients. J Acoust Soc Am 117(6):3952-3957

Marsh HW, Schulkin M (1962) Shallow-water transmission. J Acoust Soc Am 34:863-864

McCauley RD, Fewtrell J, Duncan AJ, Jenner C and 6 others (2000) Marine seismic surveys - a study of environmental implications. APPEA 40:692-708

McKenzie Macon C (2000) Off-shore wind turbine construction. Ødegaard \& Daneskiold Sample A/S, Rep. no. 00.877, SEAS, Haslev

Medwin H, Clay CS (1998) Introduction to acoustic oceanography. Chapman \& Hall, New York

Møhl B (1968) Auditory sensitivity of the common seal in air and water. J Aud Res 8:27-38

Møhl B, Andersen S (1973) Echolocation: high-frequency component in the click of the harbour porpoise (Phocoena ph. L.). J Acoust Soc Am 54:1368-1372

Nachtigall PE, Pawloski JL, Au WWL (2003) Temporary threshold shifts and recovery following noise exposure in the Atlantic bottlenosed dolphin (Tursiops truncatus). J Acoust Soc Am 113:3425-3429

Nachtigall PE, Supin AY, Pawloski J, Au WWL (2004) Temporary threshold shifts after noise exposure in the bottlenose dolphin (Tursiops truncatus) measured using evoked auditory potentials. Mar Mamm Sci 20(4):673-687

Nedwell J, Howell D (2004) A review of offshore windfarm related underwater noise sources. Cowrie Rep $544 \mathrm{R}$ 0308:1-57

Nedwell JD, Langworthy J, Howell D (2003) Assessment of subsea acoustic noise and vibration from offshore wind turbines and its impact on marine life. Cowrie Rep $544 \mathrm{R}$ 0424:1-68

Nowacek D, Johnson M, Tyack P (2004) North Atlantic right whales (Eubalaena glacialis) ignore ships but respond to alarm stimuli. Proc R Soc B 271:227-231 
NMFS (National Marine Fisheries Service) (2003) Taking marine mammals incidental to conducting oil and gas exploration activities in the Gulf of Mexico. Fedl Register 68:9991-9996

NRC (National Research Council) (2000) Marine mammals and low-frequency sound. National Academy Press, Washington, DC

NRC (National Research Council) (2003) Ocean noise and marine mammals. Ocean Study Board, National Academy Press, Washington, DC

Parks SE, Tyack PL (2005) Sound production by North Atlantic right whales (Eubalaena glacialis) in surface active groups. J Acoust Soc Am 117:3297-3306

Payne R, Webb D (1971) Orientation by means of long range acoustic signaling in baleen whales. Ann NY Acad Sci 188:110-141

Piggott CL (1964) Ambient sea noise at low frequencies in shallow water of the Scotian Shelf. J Acoust Soc Am 36: 2152-2163

Richardson WJ, Wursig B, Greene CR Jr (1986) Reactions of bowhead whales, Balaena mysticetus, to seismic exploration in the Canadian Beaufort Sea. J Acoust Soc Am 79: $1117-1128$

Richardson WJ, Greene CR, Malme CI, Thompson DH (1995) Marine mammals and noise. Academic Press, San Diego

Richardson WJ, Miller GW, Greene CR (1999) Displacement of migrating bowhead whales by sounds from seismic surveys in shallow waters of the Beaufort Sea. J Acoust Soc Am 106:2281

Rodkin RB, Reyff JA (2004) Underwater sound pressures from marine pile-driving. J Acoust Soc Am 116:2648

Scharf B (1970) Critical bands. In: Tobias JV (ed) Foundations of modern auditory theory. Academic Press, New York, p 159-203

Schlundt CE, Finneran JJ, Carder DA, Ridgway SH (2000) Temporary shift in masked hearing thresholds of bottlenose dolphins, Tursiops truncatus, and white whales, Delphinapterus leucas, after exposure to intense tones. J Acoust Soc Am 107:3496-3508

Southall BL, Schusterman RJ, Kastak D (2001) Masking in three pinnipeds: underwater low-frequency critical ratios. J Acoust Soc Am 108:1322-1326

Stafford KM, Fox CG, Clark DS (1998) Long-range acoustic detection and localization of blue whale calls in the northeast Pacific Ocean. J Acoust Soc Am 104: 3616-3625

Editorial responsibility: Howard I. Browman (Associate Editorin-Chief), Storebø, Norway
Teilmann J, Carstensen J, Dietz, R, Edrén SME (2004) Effect on seals at Rødsand seal sanctuary from the construction of Nysted offshore wind farm based on aerial surveys. Technical report to Energy E2 A/S. National Environmental Research Institute, Roskilde (also available at: http://uk.nystedhavmoellepark.dk)

Terhune JM (1999) Pitch separation as a possible jammingavoidance mechanism in underwater calls of bearded seals (Erignathus barbatus). Can J Zool 77:1025-1034

Terhune JM, Turnbull SD (1995) Variation in the psychometric functions and hearing thresholds of a harbour seal. In: Kastelein RA, Thomas JA, Nachtigall PE (eds) Sensory systems of aquatic mammals. De Spil, Woerden, p 81-93

Tougaard J, Carstensen J, Henriksen OD, Skov H, Teilmann J (2003) Short-term effects of the construction of wind turbines on harbour porpoises at Horns Reef. Technical report to Techwise A/S, HME/362-02662. Hedeselskabet, Roskilde. Also available at: www.hornsrev.dk

Tougaard J, Carstensen J, Teilmann J, Bech NI (2005a) Effects on the Nysted Offshore wind farm on harbour porpoises. Technical Report to Energi E2 A/S. NERI, Roskilde (Also available at http://uk.nystedhavmoellepark.dk)

Tougaard J, Carstensen J, Wisch MS, Teilmann J, Bech N, Skov H, Henriksen OD (2005b) Harbour porpoises on Horns reef - effects of the Horns Reef Wind farm. Annual Status Report 2004 to Elsam. NERI, Roskilde (Also available at: www.hornsrev.dk)

Tyack P (1998) Acoustic communication under the sea. In: Hopp SL, Owren MJ, Evans CS (eds) Animal acoustic communication: recent technical advances. SpringerVerlag, Heidelberg, p 163-220

Urick RJ (1983) Principles of underwater sound. Peninsula Publishing, New York

Wahlberg M, Westerberg H (2005) Hearing in fish and their reaction to sounds from offshore wind farms. Mar Ecol Prog Ser 288:295-309

Wenz G (1962) Acoustic ambient noise in the ocean: spectra and sources. J Acoust Soc Am 34:1936-1956

Westerberg H (1994) Fiskeriundersökningar vid havsbaserat vindkraftverk 1990-1993. Rapp 5-1994. Fiskeriverket, Utredningskontoret Jönköping

Willie PC, Geyer D (1984) Measurements on the origin of the wind-dependent ambient noise variability in shallow water. J Acoust Soc Am 75:173-185

Zwicker E, Schorn K (1978) Psychoacoustical tuning curves in audiology. Audiology 17:120-140

Submitted: March 12, 2005; Accepted: May 16, 2005

Proofs received from author(s): January 16, 2006 